\title{
Free convection heat transfer in an inclined channel asymmetrically heated in laminar regime
}

\author{
T. Khoualdi ${ }^{1 *}$, M. S. Rouabah ${ }^{1}$, M. Bouraoui $^{1}$, A. Abidi-Saadb ${ }^{2,3}$, G. Polidori $^{4}$ \\ ${ }^{1}$ Laboratoire de génie climatique, Département de génie climatique, Faculté des Sciences de la Technologie, Université Frères \\ Mentouri Constantine 1. Campus Ahmed Hamani, Constantine 25000, Algeria \\ ${ }^{2}$ Laboratoire d'Energétique Appliquée et de Pollution, Université Constantine 1, Constantine 25000, Algeria \\ ${ }^{3}$ A Faculté des Hydrocarbures et Energies renouvelables et Sciences de la terre et de l'univers, Université Kasdi Merbah, \\ Ouargla 30000, Algérie \\ ${ }^{4}$ GRESPI/Thermomécanique, UFR sciences Exactes et Naturelle, Campus du Moulin de la Housse-BP 1039, Reims 51687, \\ France
}

Corresponding Author Email: tarek-clim@hotmail.com

https://doi.org/10.18280/ijht.360347

Received: 5 January 2018

Accepted: 11 July 2018

\section{Keywords:}

natural convection, asymmetric heating, inclined channel, $P V$ panels, roof-top $D S F$

\begin{abstract}
This paper deals with the numerical modeling of the open flow induced by natural convection within tilted asymmetrically heated channel with constant heat flux equal to $510 \mathrm{~W} / \mathrm{m} 2$ and for a modified Rayleigh number $\mathrm{Ra}^{*}=4.5 \times 106$. The slope of the channel can vary between $0^{\circ}$ and $90^{\circ}$. The inclined channel is immerged in a tank filled with water, which represents the surrounding environment, in order to overcome the heat radiation effect and pressure conditions at the inlet and outlet of the channel. The conservation equations of mass, momentum and energy are solved using the finite volume method and the numerical simulations are performed using Ansys Fluent CFD software. The influence of the inclination of the channel on the thermal and dynamic behaviors of flow within the channel is analyzed. The results are plotted in term of local Nusselt number, streamlines, isotherms and axial velocity profiles as well.
\end{abstract}

\section{INTRODUCTION}

The main cause of interest in the study of free convection in vertical or inclined channels, is not just for the fundamental nature of the problem, but also mainly from the fact that this type of thermally driven flow is cheap, reliable, quiet and maintenance free. Also, free convection is an attractive heat transfer mechanism due to its cooling effectiveness. Furthermore, it is encountered in numerous applications such as solar chimney, Trombe wall, solar collector, vertical or roof-top double-skin façades with/without the integration of PV panels.

On the other hand, knowledge and understanding of PV panels well-functioning and its use as a renewable energy sources for the electricity production in building sector is the main cause of such researches. As common, the PV panels have high efficiency as their temperature is low. Additionally, in literature, PV panels are modeled by an inclined or vertical asymmetrically heated channel in many works as Manca et al. [1] and Rich [2]. The well understanding of the fluid flow and heat transfer behavior and their improvement within the channel formed by PV panels and building envelope, which is crucial in minimizing the overheating risk in PV devices and maximizing their efficiency. In fact, the increase of the heat transfer at PV panels and implicitly its cooling, leads to the increase in the conversion efficiency of such system. Many researchers have been conducted for this perspective.

Despite these efforts, the problem still open and a need to

deepen analyzes persists to have the well prediction of the physical phenomena that drive the flow behavior within such systems. Especially the analyzes of the geometric parameters effect such as: channel width, channel length, ribs location, sizes and shapes and channel tilt angel as well. This provides a valuable engineering informations for the design and the installations of such systems (PV panels integration in the roofs or the vertical facades), which leads to the cooling of PV devices and then increasing their efficiencies. Several studies treated natural convection in a channel representative of vertical PV double skin facades (PV-DSF). Indeed, the first experimental study was performed by Elenbaas [3]. His study showed two dynamic flow regimes in a vertical channel, depending on the modified Rayleigh number $\left(\mathrm{Ra}^{*}\right)$, which is based on the width of the channel (b) and the $\operatorname{ratio}(\mathrm{A} / \mathrm{b})$, where $A$ is the length of the heated part of the wall. The fluid enters from the bottom of the channel forming a boundary layer type flow near the heated wall, in the same time, it enters from the top of the channel via a return flow (recirculation zone) adjacent to the unheated wall (Webb and Hill [4], Azevedo and Sparrow [5]). The recent study carried out by Polidori et al. [6] for an asymmetrically heated vertical plane channel, revealed the appearance of a dynamic boundary layer type flow and a reversed flow at the channel outlet.

The heat transfer in the inclined channels (roof PV-DSF prototype) has received less attention compared to that in the vertical ones. The first experiment was performed by Rich. [2] where the average heat transfer rate along the heated wall (PV cells) at different angles up to $40 \mathrm{o}$ were measured. His experimental data indicates that the heat transfer decreases when the heated wall is moved from its vertical position. Onur et al. [7-8] provided experimental data about the effect of the inclination angle and the channel's width on developing heat transfer between inclined parallel walls with different heating 
conditions. In particular, in [7], they considered the lower plate isothermally heated and the upper plate insulated, while in [8] their experiments were performed for plate's inclination of $0 \circ$, $30^{\circ}$ and $45^{\circ}$ with respect to the vertical position. The results indicated that both the plate spacing, and inclination influence the heat transfer rate. A study presents Bianco, N et al. [9] investigations into three open ended channel configurations, which model electronic systems with heat-dissipating components at the walls. The article describes experiments and numerical studies in symmetrically and asymmetrically heated inclined channel. Utterly as well as discretely heating at the walls have been taken into account. The effects of the channel gap, of the inclination angle, of the walls emissivity, of the dissipated heat flux, of the number and the location of the discrete heat sources along the walls are reported.

An experimental investigation on air natural convection in an inclined discretely heated plate with a parallel shroud below have been carried out by Monca et al. [10]. The experiments were performed in the ranges of Ra between $\left(10^{4}\right.$ and $\left.10^{5}\right)$ and for $R_{f}$ between (10 and 32.6). In their conclusions, the authors have clearly demonstrated that increasing the distance between the shroud and the discretely heated plate affects the phenomenon in two different ways. At angles less than $85 \mathrm{deg}$, the larger the channel gap is, the weaker the chimney effect, as a consequence the higher the maximum wall temperature and at larger angles the effect is the opposite. Natural convection of air within a vertical/inclined channel (photovoltaic applications) between $15^{\circ}$ to $90^{\circ}$ degrees were conducted numerically by Lau et al. [11]. They simulate the effect of various parameters in turbulent regime on heat transfer. Their results demonstrated that the temperature distribution along the PV panel decreases with the increase of inclination angle. A numerical study of Kiwan and Khodier. [12] was carried out at steady-state natural convective heat transfer in an openended inclined channel partially filled with an isotropic porous medium. The authors performed this work to analyze the channel wall spacing (b), thermal conductivity, Darcy number (Da), inclination angle, Prandtl number (Pr) on heat transfer. It is found that the average Nusselt number reaches a minimum value when a porous media of low thermal conductivity ratio with $\mathrm{sp} / \mathrm{s}=0.5$ was used. Alzwayi and Paul. [13] analyzed numerically at transient regime free convection flow in an inclined parallel walled channel by employing turbulent model. The inclination angle of the channel is varied from $0^{\circ}$ to $85^{\circ}$ with respect to its vertical position while the distance separating the two plates is systematically reduced from 0.45 $\mathrm{m}$ to $0.06 \mathrm{~m}$. Their results showed that the average heat transfer coefficient depends on both the width and inclination angle of the channel. A study of the flow dynamics in a vertical and inclined water channel asymmetrically heated at uniform heat flux was carried out experimentally by Fatnassi et al. [14] Two sets of experiments were carried out for three values of the modified Rayleigh number $\left(\mathrm{Ra}^{*}=1,32.10^{5}, 2,19.10^{6}\right.$ and $\left.7,63.10^{6}\right)$ and three inclination angle $\left(0^{\circ},-10^{\circ}\right.$, and $\left.+10^{\circ}\right)$ in a transient regime on the fluid flow behavior. Their results show that for the studied inclination angles, a complex topological behavior in the internal flow exists. A study of the early stage regime of natural convection in an inclined channel between (20 to +20 ) and asymmetrically heated with a uniform heat flux was conducted numerically (Hemmer et al [15]). The obtained solutions indicated that the inclination angle in the studied range has a weak influence on flow structure and heat transfer.

Numerical study of natural convection inside double skin façade of one inclined wall has been undertaken by Kimouche et al. [16] Their study focused on the effect of the tilt of just one wall (the adiabatic wall) on the fluid flow and heat transfer behaviors. The results showed that the variation of the inclination angle fairly reduces the heat transfer. A complex topological behavior in the internal flow has been observed.

The use of water as working fluid seems to be very attractive, since Daghigh et al. [17] have reported that, in hot and humid climate, the cooling of PV cells is of high importance and difficult for PV/T collector systems. In the current investigation, the water was employed as working agent. The asymmetrically heated channel is immerged in a water tank, both correspond to double skin façade with integration of PV panels (roof-top or vertical) and its environment, respectively.

The aim of the present study is to increase knowledge in the field of natural convection in the channels [22]. To the authors' knowledge, it is the first time that such a study focuses on the development of reversal flows and heat transfer in tilted openended channel for a wide range of angle using water as working fluid is performed. The study is based on a numerical simulation of steady state, 2D, laminar natural convection heat transfer in an asymmetrically heated inclined channel (heated in the central part of the left wall) for which no data is available in the literature [23]. The simulation carried out with Ansys Fluent software based on finite volumes under realistic environmental conditions. The effect of channel tilt angle, $0^{\circ}$ $\leq \alpha \leq 90^{\circ}$, on heat transfer and natural convection-induced fluid flow is examined for a modified Rayleigh number $\mathrm{Ra}^{*}=$ $4,5 \times 10^{6}$ and a constant aspect ratio.

\section{FORMATION OF THE PROBLEM}

\subsection{Description of the channel}

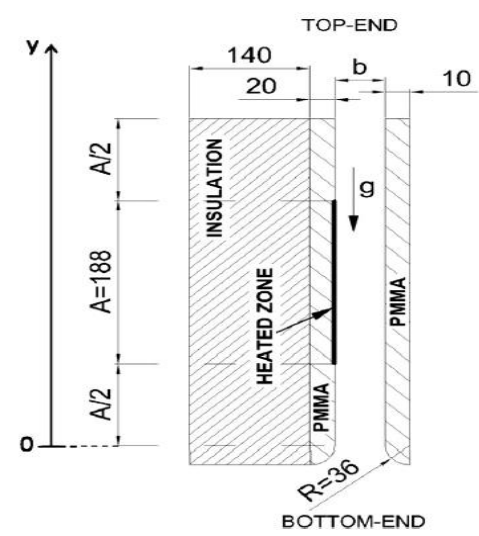

(a) Channel geometry (source [6])

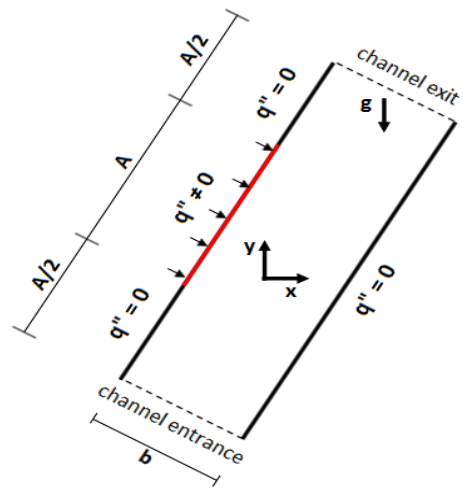

(b) Boundary conditions

Figure 1. A detailed of the studied channel 
The channel consists of two plan parallel walls spaced by a gap equal to $b=36 \mathrm{~mm}$. The first wall is composed of a central heated part of height $\mathrm{A}=188 \mathrm{~mm}$ and two adiabatic extensions of heights $\mathrm{A} / 2$, respectively located in exit and entrance of the channel. The second wall is entirely adiabatic. For better control of the flow conditions at the entrance, a quarter circle $(\mathrm{R}=36 \mathrm{~mm})$ was added at the bottom of the two channel walls (see Fig 1). The heating zone of the channel is an aluminum plate of height $\mathrm{A}=188 \mathrm{~mm}$ and $3 \mathrm{~mm}$ thick, subjected to a uniform heat flux density q" $=510 \mathrm{~W} / \mathrm{m}^{2}$ which corresponds to the average annual solar heat flux in France. The rear face of the heated wall is made adiabatic by adding a layer of $140 \mathrm{~mm}$ thick Styrofoam to minimize heat loss and to prevent the onset of convection in the external environment. The vertical channel is immersed in a tank of water of dimensions $500 * 500 * 1000 \mathrm{~mm}^{3}[6]$. The use of water allows to overcome the heat radiation effect.

\subsection{Physical Model}

To simplify the model that describes the natural convection in the plan channel, some simplifying assumptions are imposed. In this study, it is assumed that the flow is laminar, two dimensional and steady. The fluid is assumed to be incompressible, Newtonian and fluid physical properties depend only on the temperature as stated in [15] and [18]. Natural convection is governed by the continuity (1), the momentum (2 and 3 ) and the energy (4) equations, as follows:

$$
\begin{aligned}
& \frac{\partial}{\partial x}=0 \\
& \rho\left[\frac{\partial u}{d t}+u \frac{\partial u}{\partial x}+v \frac{\partial u}{\partial y}\right]=-\frac{\partial p^{*}}{\partial x}+\mu\left[\frac{\partial^{2} u}{\partial x^{2}}+\frac{\partial^{2} u}{\partial y^{2}}\right]+\frac{\partial u}{\partial x} \frac{\partial \mu}{\partial x}+\frac{\partial v}{\partial x} \frac{\partial \mu}{\partial y}-\rho g_{x} \\
& \rho\left[\frac{\partial v}{\partial t}+u \frac{\partial v}{\partial x}+v \frac{\partial v}{\partial y}\right]=-\frac{\partial p^{*}}{\partial y}+\mu\left[\frac{\partial^{2} v}{\partial x^{2}}+\frac{\partial^{2} v}{\partial y^{2}}\right]+\frac{\partial u}{\partial y} \frac{\partial \mu}{\partial x}+\frac{\partial v}{\partial y} \frac{\partial \mu}{\partial y}-\rho g_{y} \\
& \rho c_{p}\left[\frac{\partial \mathrm{T}}{\partial t}+u \frac{\partial \mathrm{T}}{\partial x}+v \frac{\partial \mathrm{T}}{\partial y}\right]=k\left[\frac{\partial^{2} \mathrm{~T}}{\partial x^{2}}+\frac{\partial^{2} \mathrm{~T}}{\partial y^{2}}\right]
\end{aligned}
$$

Simulations were conducted for a modified Rayleigh number $\left(\mathrm{Ra}^{*}\right)$ equal to $4.5 \times 10^{6}$. The modified Rayleigh number is based on the flux density and the thickness of the channel (b) and also takes in to account the aspect ratio of the heated part $(\mathrm{A} / \mathrm{b})$ through equation $(5)$

$$
\operatorname{Ra}^{*}=\frac{8 \boldsymbol{B q}^{\prime \prime} \mathrm{b}^{4}}{\mathrm{Ke}^{2}} \frac{\mathrm{b}}{A} \mathrm{Pr}_{\mathbf{r}}
$$

\subsection{Numerical Method}

The governing equations (Eq. 1-4) are solved numerically using the finite volume method. The numerical simulations are performed with the commercial software ANSYS Fluent CFD where the same model performed in [19] and [20] is used.

The used mesh is represented in Figure 2 it is structured inside the channel and not structured and progressive in the outer calculation field. Several grid refinement experiments inside the channel were performed $(7000,7500,8000,8600$, 8730 and 9000) relative to the mass flow rate to determine the suitable grid size required for the numerical simulation, for the case of $\mathrm{Ra}^{*}=4.5 \times 10^{6}$ and inclination angle equal to $20^{\circ}$. At the end of the preliminary calculations, a grid size 8730 was judged sufficient to get results with a satisfactory precision, which corresponds to 12259 cells in the entire calculation domain. This grid was used to carry out the final computations. Because there is no much improvement in precision, successive mesh refinement leads to a change in values occurring in the fourth digit after the decimal point, with a relative error in the mass flow rate less than $2 \%$.

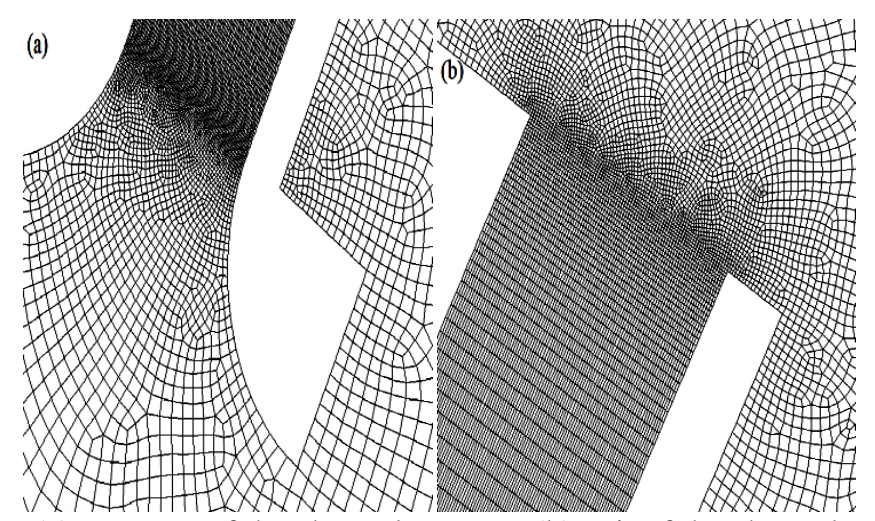

(a) entrance of the channel

(b) exit of the channel

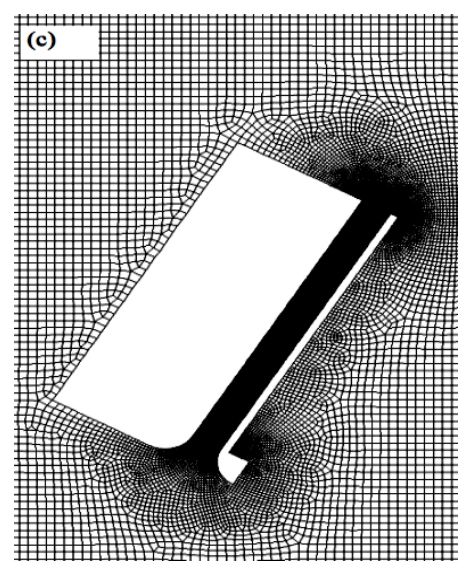

(c) Mesh structure

Figure 2. Detailed view of the mesh around the channel

In the solver configuration, the "pressure-based" solver is used. This solver solves the equations of transport in a sequential manner. However, the coupling between the velocity and the pressure is achieved with the "Coupled Scheme" algorithm that allows to simultaneously solve the equations of continuity and momentum, giving advantage to the treatment of the flows with a strong interdependence between thermal and dynamic fields. The adopted convergence criterion is defined when the residuals of physical quantities become less than $10^{-6}$.

\section{VALIDATION}

It is necessary to check that the numerical model developed is reliable or not. To perform this step, the present numerical dynamic results are compared with experimental data of [21].

In Figure 3(a) a comparison of the streamlines between experimentation and current numerical simulation is made for the same geometrical and thermal configuration obtained for the case $0^{\circ}$ where the tilt angle is zero degree for a modified Rayleigh number of $4.5 \times 10^{6}\left(\mathrm{q}^{\prime \prime}=510 \mathrm{~W} / \mathrm{m}^{2}\right)$ at $\mathrm{t}=30 \mathrm{~min}$ 
which seems to be a sufficient time to reach the establishment of a steady-state flow inside the channel.

From this comparison the dynamic structure of the flow is almost the same for both studies. The two flow structures are of boundary layer type near the hot wall with a large recirculation zone adjacent to the adiabatic wall at the outlet of channel and almost of the same shape and the same length. This recirculation zone extends over three quarters of the channel height.

Figure 3(b) illustrates the comparison of the spatial evolution of the temperature gradient at the heated zone (thermal field). From both experimental (Polidori et al [6]) and actual numerical results, a very good agreement between curves is found.

It can be seen from these figures, Figure 3(a) and Figure 3(b), that both experimental and numerical thermal and dynamical fields fit very well which gives more confidence to our numerical model.
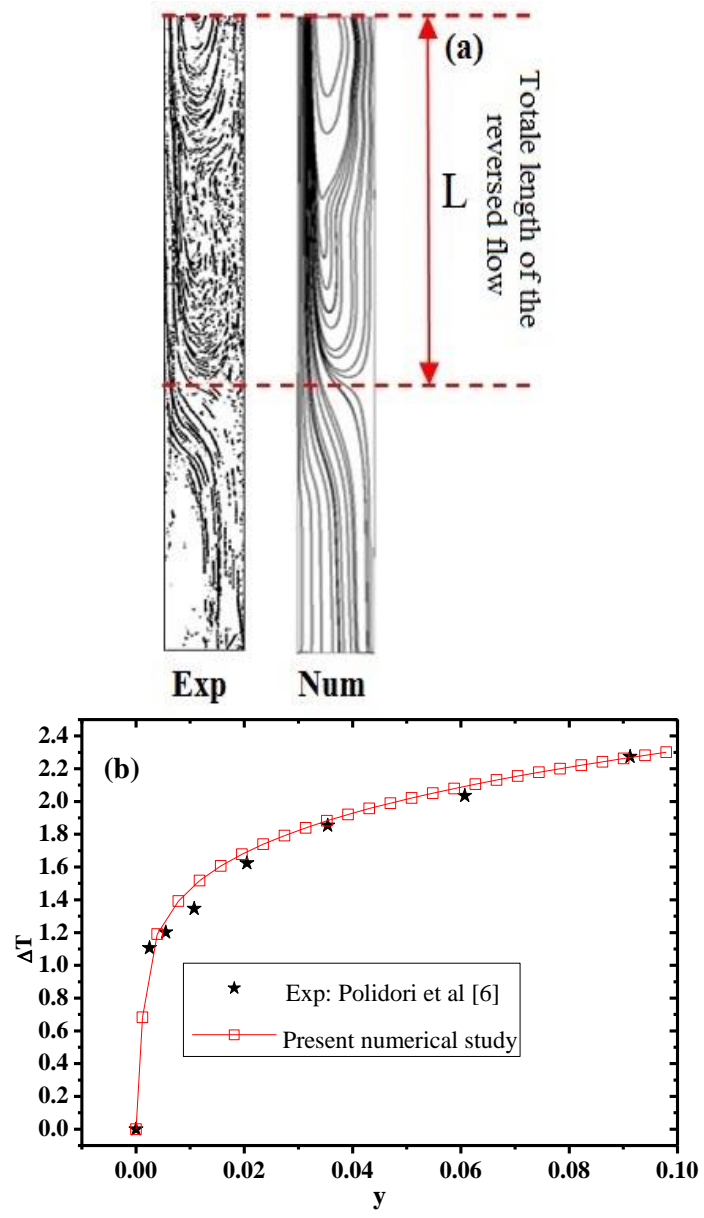

Figure 3. Model validation: (a) Flow structure; (b) Temperature profiles along the vertical heated wall

\section{RESULTS}

In this study, the results obtained for a modified Rayleigh number equal to $\mathrm{Ra}^{*}=4.5 \times 10^{6}$, reflecting a natural convection induced flow in laminar regime with a heat flux density $510 \mathrm{~W} / \mathrm{m}^{2}$. We seek to determine the inclination effect of an asymmetrically heated channel on fluid flow and heat transfer behavior induced by natural convection. The considered inclinations are: $\alpha=0^{\circ}, 10^{\circ}, 20^{\circ}, 30^{\circ}, 40^{\circ}, 50^{\circ}, 60^{\circ}, 70^{\circ}, 80^{\circ}$, $90^{\circ}$.

\subsection{The influence of the channel's inclination angle on the} flow structure and the temperature field

The results are presented after 30 minutes of heating where the steady state is fulfilled. For all studied cases, it is observed that, an upward flow of boundary layer type developed along the heated wall coming from the entrance of the channel fed with cold fluid. In addition, a cold fluid feeding was noticed at the exit of the channel nearby the unheated wall forming the reversed flow. The comparison of results for the selected angles shows that the inclination plays a significant role on the depth of the circulation zone size. It can be seen from Figure 4 that a global decrease of the recirculation zone size when the channel moves from the vertical position. In addition, a progressively decrease of the recirculation zone size has been observed for inclination angles between $50^{\circ}$ and $80^{\circ}$.

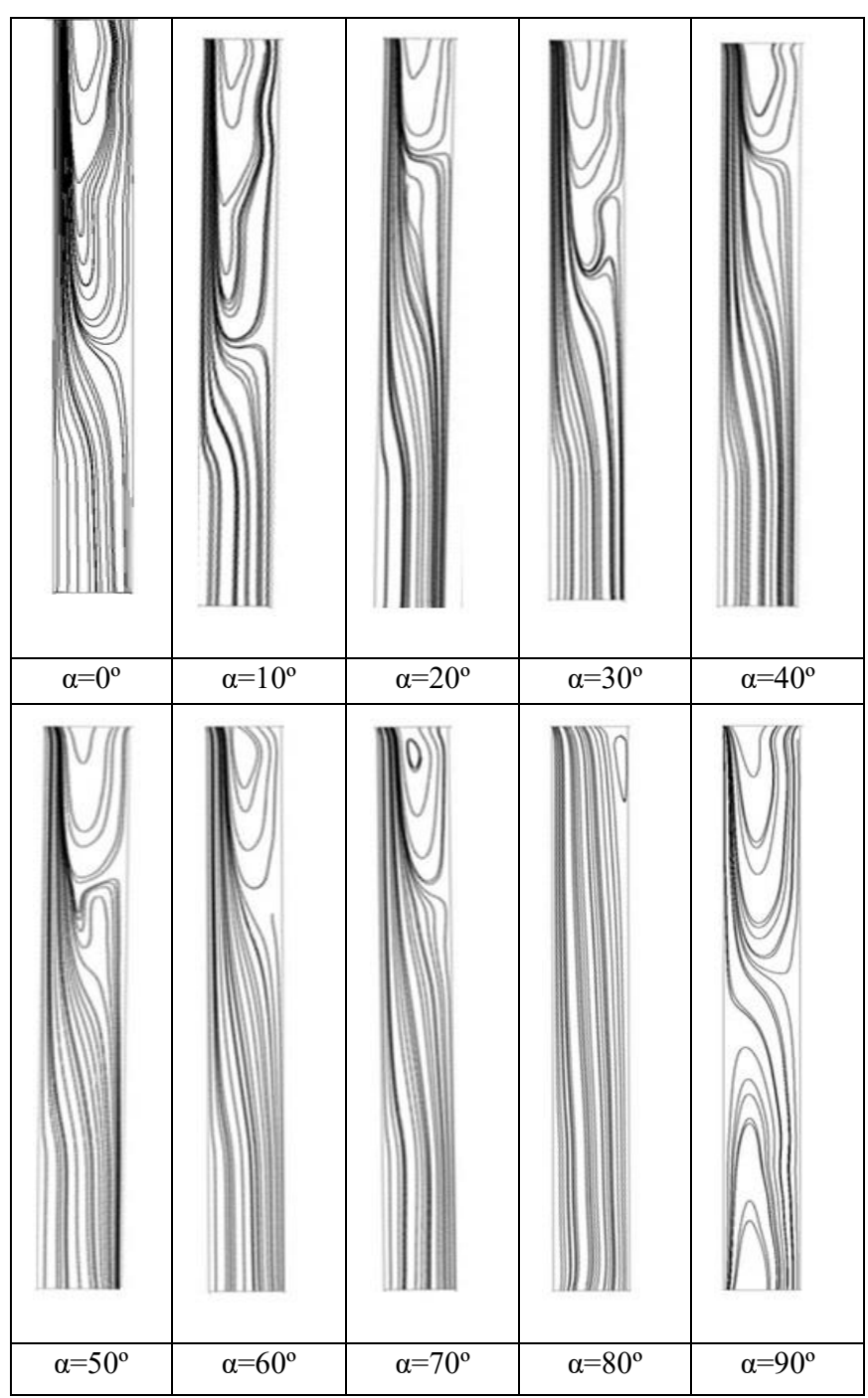

Figure 4. Streamline patterns in the channel at $\mathrm{Ra}=4.5 \times 10^{6}$ for the different angles

Whereas, a sinusoidal variation of the recirculation zone size is reached for inclination angles from $20^{\circ}$ to $40^{\circ}$. While, a weak variation (decrease) has also been observed at $10^{\circ}$ from the vertical position. On the other hand, when the inclination of the channel tends to the horizontal position $\left(90^{\circ}\right)$, two recirculation zones were revealed, one is at the channel inlet near the heated wall and the other appears at the channel outlet adjacent to adiabatic wall (See Figure 4). 
Figure 5 shows that the effect of the inclination angle on the temperature field within the studied channel for an angle varying from $0^{\circ}$ to $70^{\circ}$, has no influence on the thermal boundary layer. However, it can be seen that the inclination of $80^{\circ}$ produces a slight increase in the thickness of the thermal boundary layer. Finally, this increase in the thickness becomes important and occupies the entire height of the channel heated wall for the horizontal position $\left(90^{\circ}\right)$. This phenomenon is explained by the fact that when the channel tends to the horizontal position, the hot fluid moves up by difference of density in the opposite direction of gravity (buoyancy) and therefore remains close to the heated wall, Thermal expansion of the boundary layer is so affected by this process and the heat transfer between the walls.

\subsection{The influence of the channel's inclination angle on the axial velocity at inlet and the outlet of the channel}

Figure 6 shows the axial velocity profiles at the entrance of the studied channel for different angles of inclination. It can be seen that the same velocity profile, for the vertical position $\alpha$ $=0^{\circ}$, is observed as found in [19] which presents a symmetrical profile. In addition, the increase of the channel inclination angle to $30^{\circ}$ increases the vertical velocity at the channel entrance, compared to the reference case $\left(\alpha=0^{\circ}\right)$. While, the maximum velocity is obtained for an angle equal to $20^{\circ}$.

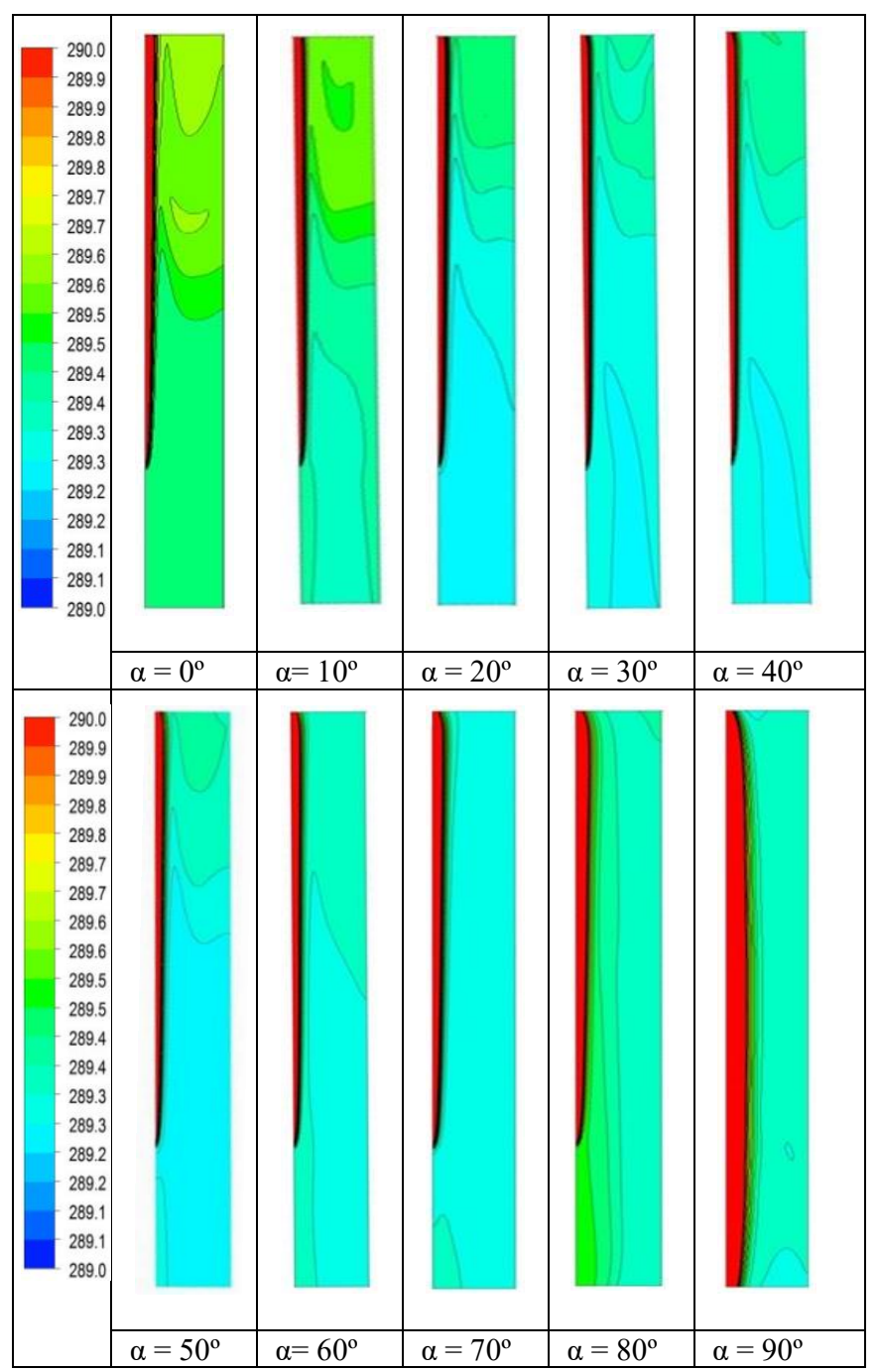

Figure 5. Isotherm patterns in the channel at $\mathrm{Ra}=4.5 \times 10^{6}$ for the different angles
This is due to the decrease in the recirculation zone size affected by mass flow rate through the entrance of the channel. When the inclination angle reaches a higher value than $40^{\circ}$, one can see that the velocity deceases with the increase of the inclination angle. Because, at these values the flow at the entrance of the channel is affected by the adiabatic extension playing a role of a rib which it reduces the axial velocity. Negative values of the axial velocity in the channel slope reaches or exceeds an inclination angle of $80^{\circ}$.

From Figure 7, it can be seen that, for an inclination angle varying from $0^{\circ}$ to $80^{\circ}$, the axial velocity profiles at the channel exit has always the shape of boundary layer type flow with a strong acceleration in vicinity of the heated wall due to the narrow passage section between the hot wall and the reversed flow.

Negative velocities are observed near the unheated wall for almost all cases varying between $0^{\circ}$ and $80^{\circ}$ indicating the presence of a reversed flow. Therefore, when the inclination angle reaches the horizontal position of $90^{\circ}$, the velocity has a maximum near the unheated wall and flattened away from this later.

\subsection{Heat transfer}

According to Figures. 8 and 9, the local Nusselt number and temperature variations are depending on the inclination angle of the channel. From Figure 8 it can be observed that the local Nusselt number at the heated wall decreases when the slop of the channel increases with a higher value than $30^{\circ}$. Also, the figure indicates that, for the horizontal position i.e., inclination angle equals to $90^{\circ}$, the local Nusselt number has a flat profile and its value represents the lowest value in comparison with the other studied cases.

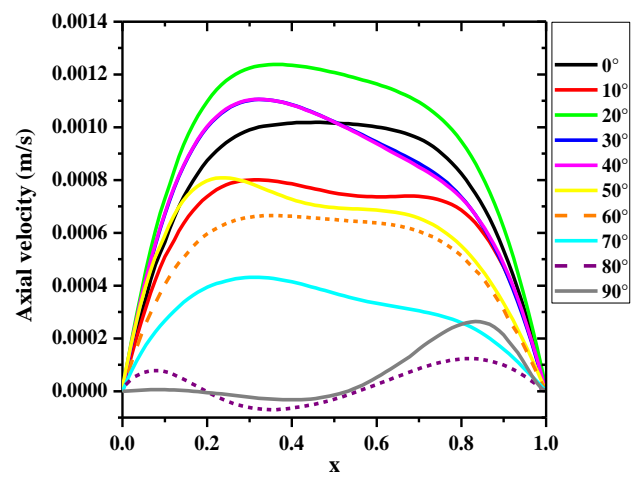

Figure 6. Axial velocity profiles at the entrance of the channel for all inclination angles

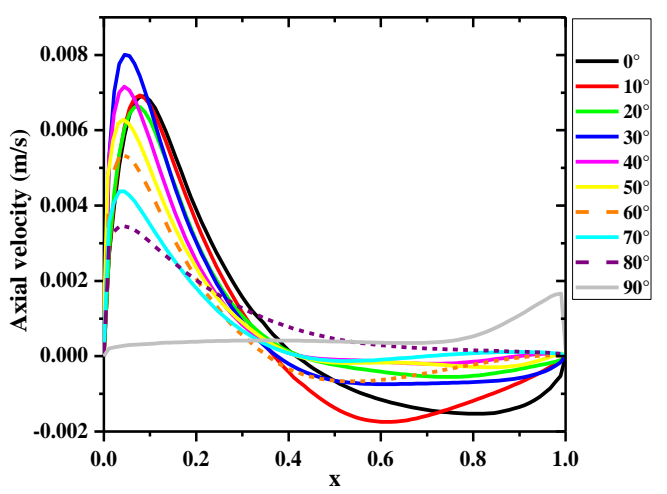

Figure 7. Axial velocity profiles at the exit of the channel for all inclination angles 


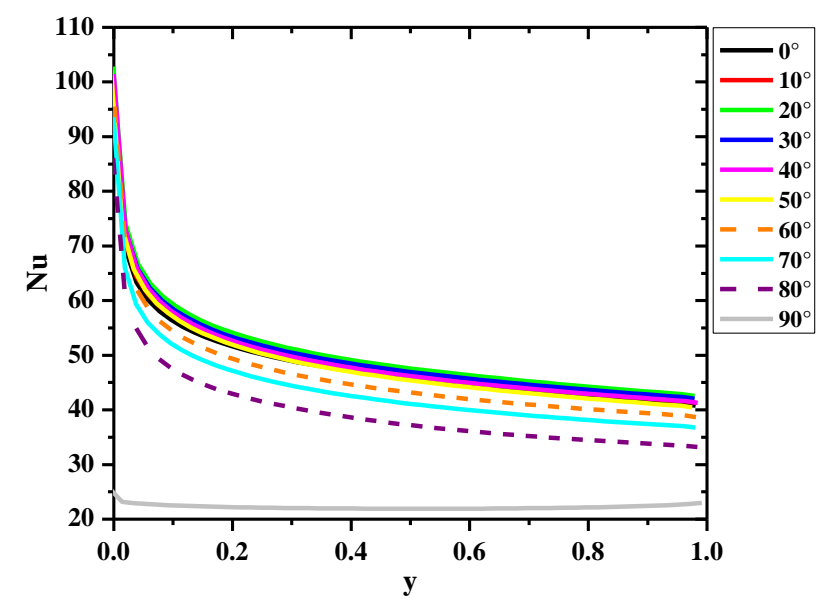

Figure 8. local Nusselt number along the vertical heated wall for all inclination angles

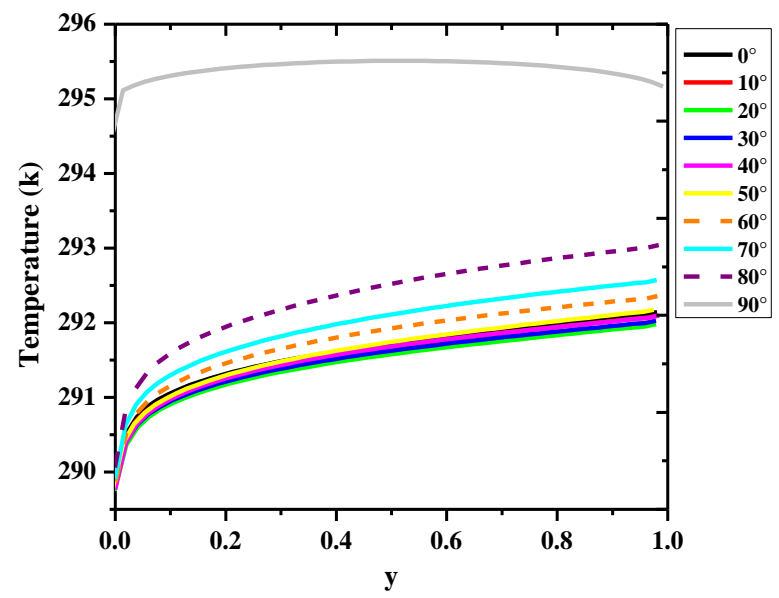

Figure 9. Temperature profiles along the vertical heated wall for all inclination angles

However, one can observe for temperature variations on the heated wall (Figure 9) that, increasing the inclination angle above $20^{\circ}$ leads to the increase of the temperature at the heated wall. It reached its maximum for an angle equals to $90^{\circ}$.

The results presented on Figure 10 allow to observe the effect of the inclination angles from $0^{\circ}$ to $90^{\circ}$ on the temperature difference at different heights within the channel at the channel inlet, at the entrance of the heated zone, at the middle of the heated zone, at the exit of the heated zone and at the outlet of the heated wall for a modified Rayleigh number $\mathrm{Ra}^{*}=4.5 \times 10^{6}$.

On this figure, one may observe that, the temperature is high near the heated wall and it decreases far from this later for all studied cases. It is observed that small inclination angles between $0^{\circ}$ to $10^{\circ}$ decreases the temperature variation. In addition, the inclination angles from $20^{\circ}$ to $40^{\circ}$ has no effect on the temperature variation within the channel. Although, it seems that the increase of the inclination angles from $50^{\circ}$ causes the increase in the temperature. According to this, the more the inclination angles is higher than this value, the more the temperature difference is important.

\section{CONCLUSIONS}

The present numerical study revealed the results of natural convection in tilted asymmetrically heated channel representative of double skin facades or PV panels. The channel is tilted with an angle varied from $0^{\circ}$ to $90^{\circ}$. Both heat transfer and flow dynamics aspects are considered, for a modified Rayleigh number equal to $\mathrm{Ra}^{*}=4.5 \times 10^{6}$ and under realistic environmental conditions using flux density of $510 \mathrm{~W} / \mathrm{m}^{2}$ corresponding to the average environmental conditions of insulation in France. The following summarize the present paper:

- Whatever the inclination angle of the channel, a boundary layer type flow develops along the heated wall accompanied with a recirculation zone at the channel outlet near the unheated wall have been highlighted. Furthermore, the increase of the inclination angle from $50^{\circ}$ to $80^{\circ}$ decreases the depth of the recirculation zone.

- The maximum values of axial velocity at the entrance and the exit of the channel has been obtained for the inclination angle $20^{\circ}$. Moreover, the decrease of the velocity at both the entrance and the exit of the channel is highlighted for an angle greater than $20^{\circ}$.

- The maximal heat transfer rate is found for the inclination angle $\alpha=20^{\circ}$. For large channel inclination angles $\left(80^{\circ}\right.$ to $90^{\circ}$ ) the heat transfer rate is low.

- An inclination of $90^{\circ}$ from the vertical position trained respectively a maximum and relatively low temperature and local Nusselt number at the heated wall. While the other values of the inclination less than $90^{\circ}$ affect the temperature and the Nusselt number at the heated wall, and so the heat transfer.

- The inclination angles in the range between $\left(0^{\circ}\right.$ to $\left.50^{\circ}\right)$ have a weak influence on temperature difference within the channel. However, this later increases with the increase of the inclination angles and reach its maximum for a horizontal position $90^{\circ}$.
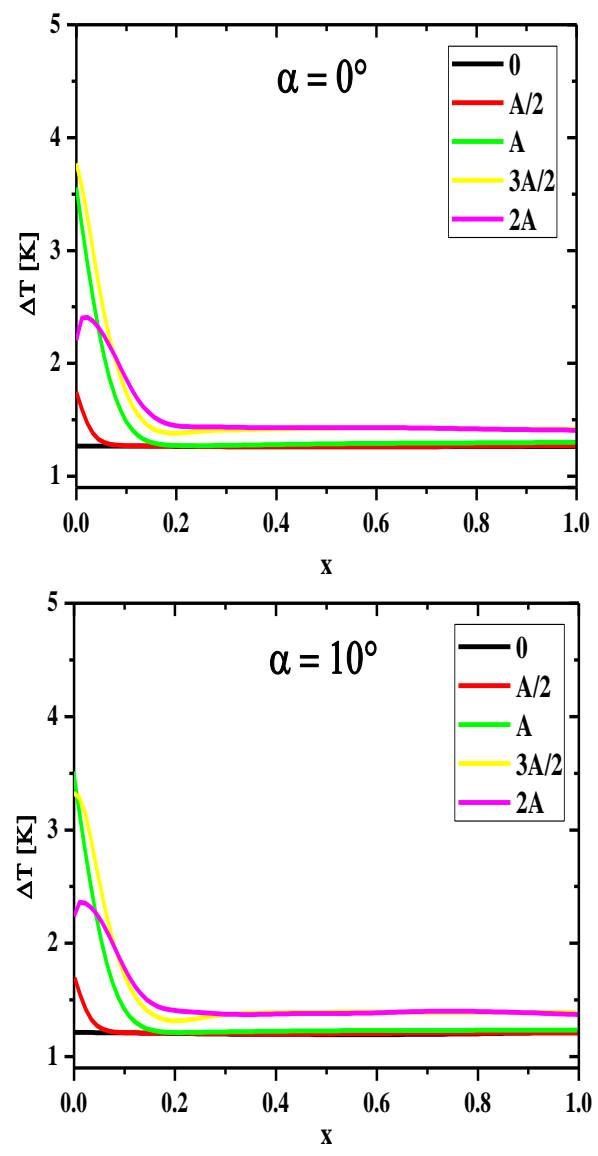

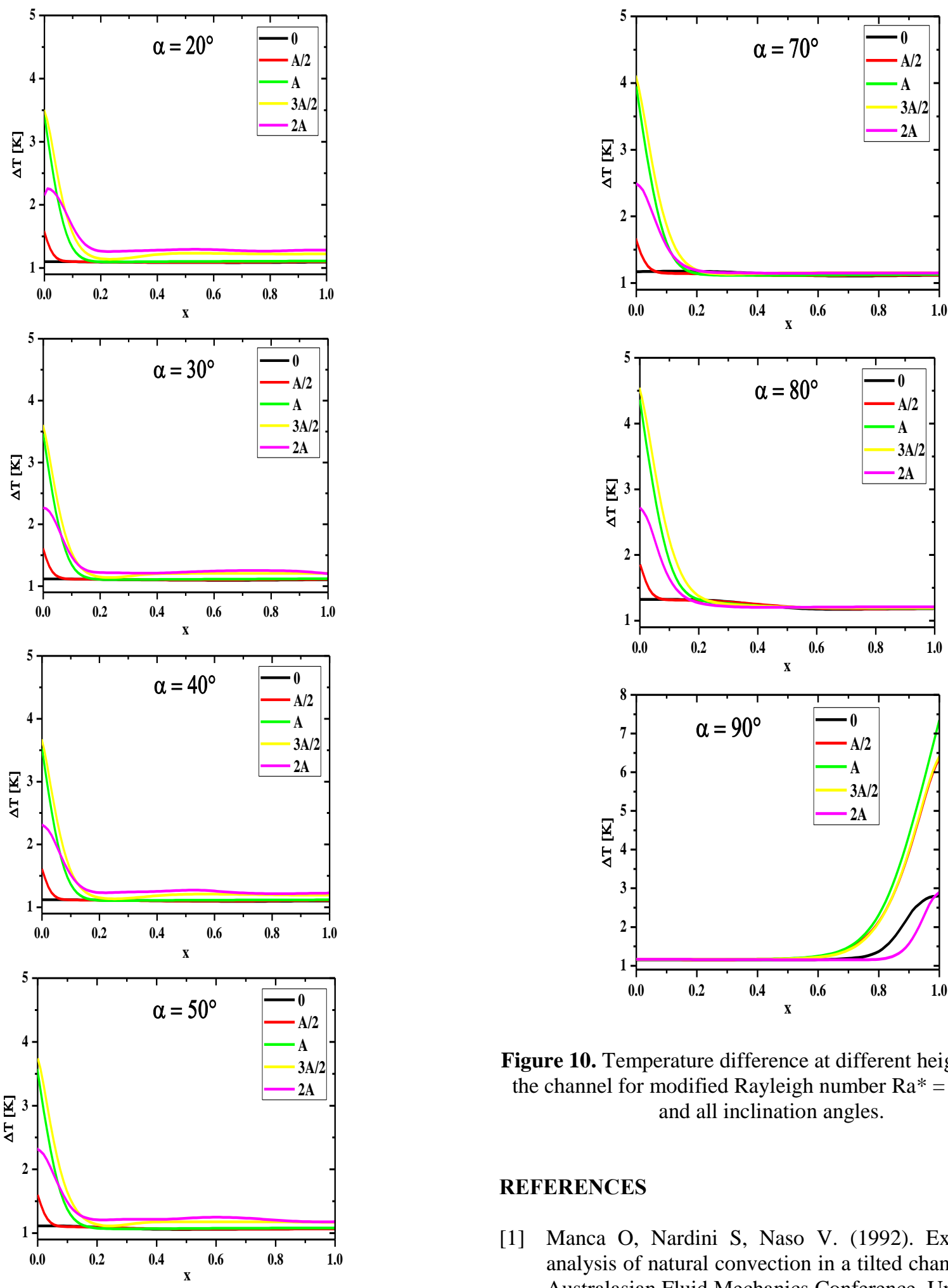

Figure 10. Temperature difference at different heights within the channel for modified Rayleigh number $\mathrm{Ra}^{*}=4.5 \times 10^{6}$ and all inclination angles.

\section{REFERENCES}

[1] Manca O, Nardini S, Naso V. (1992). Experimental analysis of natural convection in a tilted channel. 11 the Australasian Fluid Mechanics Conference, University of Tasmania, Hobart, Australia, pp. 131-134

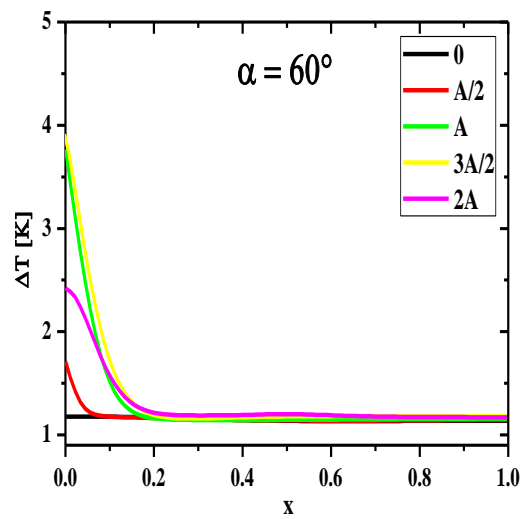

[2] Rich RB. (1953). An investigation of heat transfer from an inclined flat plate in free convection, Trans. ASME J. Heat Transfer 75: 489-499.

[3] Elenbaas W. (1942). Heat dissipation of parallel plates by free convection. Physica 9(9): 1-23. https://doi.org/10.1016/S0031-8914(42)90053-3

[4] Weeb BW, Hill DP. (1989). High Rayleigh number laminar natural convection in an asymmetrical heated vertical channel. ASME J. Heat transfer 111: 649-656. https://doi.org/10.1115/1.3250732

[5] Azevedo LF, Sparrow EM. (1986). Natural convection in a vertical channel vented to the ambient through an 
aperture in the channel wall. International Journal of Heat and Mass Transfer 29: 819-830. https://doi.org/10.1016/0017-9310(86)90178-X

[6] Polidori G, Fatnassi S, Ben Maad R, Fohanno S, Beaumont F. (2015). Early-stage dynamics in the onset of free-convective reversal flow in an open-ended channel asymmetrically heated. International Journal of Thermal Sciences 88: 40-46. https://doi.org/10.1016/j.ijthermalsci.2014.09.011

[7] Onur N, Sovrioglu M, Aktas MK. (1997). An experimental study on the natural convection heat transfer between inclined plates (lower plate isothermally heated and the upper plate thermally isolated as well as unheated). Heat and Mass Transfer 32: 471-47. https://doi.org/10.1007/s002310050147

[8] Onur N, Aktas MK. (1998). An experimental study on the effect of opposing wall on natural convection along an inclined hot plate facing downward. International Communications in Heat and Mass Transfer 25: 389-397. https://doi.org/10.1016/S0735-1933(98)00026-8

[9] Bianco N, Morrone B, Nardini S, Naso V. (2000). Air natural convection between inclined parallel plates with uniform heat flux at the walls. International Journal of

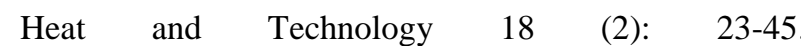
https://doi.org/10.18280/ijht180205

[10] Manca O, Nardini S, Naso V. (2002). Effect on natural convection of the distance between an inclined discretely heated plate and a parallel shroud below. ASME.J. Heat Transf. 124: 441-451. https://doi.org/10.1115/1.1470488

[11] Lau GE, Sanvicente E, Yeoh GH, Timchenko V, Fossa M, Ménézo C, Giroux-Julien S. (2012). Modelling of natural convection in vertical and tilted photovoltaic applications. Energy and Buildings 55: 810-822. https://doi.org/10.1016/j.enbuild.2012.10.014

[12] Kiwan S, Khodier M. (2012). Natural convection heat transfer in an open-ended inclined channel-partially filled with porous media. Heat Transfer Engineering 29(1): $67-75$. https://doi.org/10.1080/01457630701677205

[13] Alzwayi AS, Paul MC. (2014). Transition of free convection flow inside an inclined parallel walled channel: effects on inclination angle and width of the channel. Int. J. Heat Mass Transf. 68: 194-202. https://doi.org/10.1016/j.ijheatmasstransfer.2013.09.015

[14] Fatnassi S, Ben Maad R, Abidi-Saad A, Polidori G. (2017). On the appearance of natural convection induced reversed flow: Precocious hydrodynamic experimental study; Application to PV-DSF systems. Applied Thermal Engineering 127: 1598-1607. https://doi.org/10.1016/j.applthermaleng.2017.09.093

[15] Hemmer C, Abidi Saad A, Popa CV, Polidori G. (2017). Early development of unsteady convective laminar flow in an inclined channel using CFD: Application to PV panels. Solar Energy 146: 221-229. https://doi.org/10.1016/j.solener.2017.02.050

[16] Kimouche N, Mahri Z, Abidi - Saad A, Popa C, Polidori G, Maalouf C. (2017). Effect of inclination angle of the adiabatic wall in asymmetrically heated channel on natural convection: Application to double-skin façade design. Journal of Building Engineering 12: 171-177. https://doi.org/10.1016/j.jobe.2017.06.002

[17] Daghigh R, Ruslan MH, Sopian K. (2011). Advances in liquid based photovoltaic/ thermal (PV/T) collectors, Renew. Sustain. En ergy Res. 15: 4156-4170. https://doi.org/10.1016/j.rser.2011.07.028

[18] Abidi-Saad A, Kadja M, Popa CV, Polidori G. (2016). Effect of adiabatic square ribs on natural convection in an asymmetrically heated channel, Heat Mass Transfer 53: 743. https://doi.org/10.1007/s00231-016-1853-y

[19] Hemmer C, Popa CV, Polidori G. (2016). Heat and fluid flow in an uneven heated chimney. International Journal of Thermal Sciences 107: 220-229. https://doi.org/10.1016/j.ijthermalsci.2016.04.015

[20] Bouraoui M, Rouabah MS, Abidi-Saad A, Korichi A, Popa CV, Polidori G. (2017). numerical simulation of a double skin with secondary ventilation flow on adiabatic wall. Frontiers in Heat and Mass Transfer (FHMT): 8-18. https://doi.org/10.5098/hmt.8.18

[21] Ospir D, Popa C, Chereches NC, Polidori G, Fohanno S. (2012). Flow visualization of natural convection in a vertical channel with asymmetric heating. International Communications in Heat and Mass Transfer 39: 486-493. https://doi.org/10.1016/j.icheatmasstransfer.2012.02.00 5

[22] Tao M, Guo K, Liu H, Liu C. (2017). An evolutionary optimization method to design shapes of flow channels. Chemical Engineering Transactions 61: 1513-1518. https://doi.org/10.3303/CET1761250

[23] Rum A, Landucci G, Galletti C, Tognotti L. (2017). Cfd simulation of natural convection flow in pressurized tanks exposed to fire. Chemical Engineering Transactions $\quad 57$ 1285-1290. https://doi.org/10.3303/CET1757215

\section{NOMENCLATURE}

A

$\mathrm{C}_{\mathrm{p}}$

g

$\mathrm{k}$

$\mathrm{Nu}$

$\operatorname{Pr}$

$\mathrm{T}$

$\mathrm{q}^{\prime \prime}$

$u, v$

$x, y$

$\mathrm{Ra}$

$\mathrm{Ra}^{*}$

$\mathrm{P}^{*}$

\section{Greek symbols}

$\alpha$

$\beta$

$\rho$

$v$

$\mu$ height, $m$

specific heat, $\mathrm{J}^{\mathrm{kg}^{-1}} \cdot \mathrm{K}^{-1}$

gravitational acceleration, $\mathrm{m} \cdot \mathrm{s}^{-2}$ thermal conductivity, W. $\mathrm{m}^{-1}$. $\mathrm{K}^{-1}$

local Nusselt number

Prandtl number

temperature, $\mathrm{K}$

heat flux density, W.m-2

velocity, $\mathrm{m} . \mathrm{s}^{-1}$

coordinate, $\mathrm{m}$

Rayleigh number

modified Rayleigh number

driving pressure, $\mathrm{Pa}$ inclination angle, ${ }^{\circ}$

volume expansion coefficient, $\mathrm{K}^{-1}$

density, kg. $\mathrm{m}^{-3}$

kinematic viscosity, $\mathrm{m}^{2} \cdot \mathrm{s}^{-1}$

dynamic viscosity, Pa.s 